\title{
Birthweight and risk markers for type 2 diabetes and cardiovascular disease in childhood: the Child Heart and Health Study in England (CHASE)
}

\author{
Claire M. Nightingale • Alicja R. Rudnicka • Christopher G. Owen • Sian L. Newton • \\ Jennifer L. Bales • Angela S. Donin • Cathy M. McKay • Phillip J. Steer • \\ Debbie A. Lawlor • Naveed Sattar • Derek G. Cook • Peter H. Whincup
}

Received: 25 July 2014 / Accepted: 24 November 2014 / Published online: 18 December 2014

(C) The Author(s) 2014. This article is published with open access at Springerlink.com

\begin{abstract}
Aims/hypothesis Lower birthweight (a marker of fetal undernutrition) is associated with higher risks of type 2 diabetes and cardiovascular disease (CVD) and could explain ethnic differences in these diseases. We examined associations between birthweight and risk markers for diabetes and CVD in UKresident white European, South Asian and black AfricanCaribbean children.

Methods In a cross-sectional study of risk markers for diabetes and CVD in 9- to 10-year-old children of different ethnic origins, birthweight was obtained from health records and/or parental recall. Associations
\end{abstract}

Electronic supplementary material The online version of this article (doi:10.1007/s00125-014-3474-7) contains peer-reviewed but unedited supplementary material, which is available to authorised users.

C. M. Nightingale $(\square) \cdot$ A. R. Rudnicka $\cdot$ C. G. Owen •

S. L. Newton · J. L. Bales · A. S. Donin • C. M. McKay •

D. G. Cook $\cdot$ P. H. Whincup

Population Health Research Institute, St George's University of

London, Cranmer Terrace, London SW17 0RE, UK

e-mail: c.nightingale@sgul.ac.uk

P. J. Steer

Academic Department of Obstetrics and Gynaecology, Imperial

College London, Chelsea and Westminster Hospital, London, UK

D. A. Lawlor

MRC Integrative Epidemiology Unit, University of Bristol,

Bristol, UK

D. A. Lawlor

School of Social and Community Medicine, University of Bristol, Bristol, UK

N. Sattar

Institute of Cardiovascular and Medical Sciences, BHF Glasgow

Cardiovascular Research Centre, University of Glasgow,

Glasgow, UK between birthweight and risk markers were estimated using multilevel linear regression to account for clustering in children from the same school.

Results Key data were available for 3,744 (66\%) singleton study participants. In analyses adjusted for age, sex and ethnicity, birthweight was inversely associated with serum urate and positively associated with systolic BP. After additional height adjustment, lower birthweight (per $100 \mathrm{~g}$ ) was associated with higher serum urate $(0.52 \% ; 95 \%$ CI $0.38,0.66)$, fasting serum insulin $(0.41 \% ; 95 \%$ CI $0.08,0.74), \mathrm{HbA}_{1 \mathrm{c}}$ $(0.04 \% ; 95 \%$ CI $0.00,0.08)$, plasma glucose $(0.06 \%$; $95 \%$ CI $0.02,0.10)$ and serum triacylglycerol $(0.30 \% ; 95 \%$ CI 0.09 , 0.51) but not with BP or blood cholesterol. Birthweight was lower among children of South Asian (231 g lower; 95\% CI $183,280)$ and black African-Caribbean origin (81 g lower; $95 \%$ CI 30,132 ). However, adjustment for birthweight had no effect on ethnic differences in risk markers.

Conclusions/interpretation Birthweight was inversely associated with urate and with insulin and glycaemia after adjustment for current height. Lower birthweight does not appear to explain emerging ethnic difference in risk markers for diabetes.

Keywords Birthweight - Cardiovascular disease . Childhood $\cdot$ Ethnicity $\cdot$ Type 2 diabetes

$\begin{array}{ll}\text { Abbreviations } \\ \text { CHASE } & \text { Child Heart and Health Study in England } \\ \text { CVD } & \text { Cardiovascular disease } \\ \text { FMI } & \text { Fat mass index } \\ \text { IR } & \text { Insulin resistance } \\ \text { NS-SEC } & \text { National Statistics Socioeconomic Classification }\end{array}$




\section{Introduction}

Risks of adult chronic diseases, particularly type 2 diabetes and cardiovascular disease (CVD), appear to originate in early life, possibly before birth $[1,2]$. Lower birthweight (a marker of fetal undernutrition) has been associated with increased risks of both type 2 diabetes [3] and CVD [4]. However, in many countries, ethnic minority populations have higher risks of type 2 diabetes and CVD and lower mean birthweights, raising the possibility that lower birthweight may be an important determinant of ethnic differences in risks of these diseases [5]. In the UK, South Asians have markedly higher risks of type 2 diabetes, coronary heart disease and stroke compared with white Europeans [6-8], while black AfricanCaribbeans have higher risks of type 2 diabetes and stroke [6-8]. These ethnic differences in type 2 diabetes and cardiovascular risks are already apparent in childhood $[9,10]$. Both South Asians and black African-Caribbeans in the UK have lower mean birthweights and an increased prevalence of low birthweight compared with white Europeans [11]. However, the extent to which ethnic differences in birthweight can account for emerging ethnic differences in type 2 diabetes and CVD risks remains unknown.

We therefore examined the associations between birthweight and risk markers for type 2 diabetes and CVD at both individual and ethnic group levels in children of South Asian, black African-Caribbean and white European origin in the UK and examined the contribution of ethnic differences in birthweight to ethnic differences in these risk markers. Examining the associations between birth size and risk markers in childhood poses important analytical challenges. Childhood size is an important determinant of risk markers for type 2 diabetes and CVD and is also related to size at birth. Adjustment for current body size may affect estimates of association between birth size and disease risk markers and should attempt to estimate the longer term effect of birthweight on disease risk $[12,13]$; inappropriate adjustment could be misleading [14]. Our analyses follow an earlier approach [12] in distinguishing between two components of child size, height and body fatness, which are differently associated with risk markers over the life course [15]. Because variation in birthweight or in fetal growth rate (represented by birthweight adjusted for gestational age) could be more important [3], we have analysed associations between birthweight and risk markers both with and without adjustment for gestational age.

\section{Methods}

Study design The Child Heart and Health Study in England (CHASE) was a cross-sectional investigation of the cardiovascular and type 2 diabetes risk profiles of children aged 9-
10 years of white European, South Asian and black AfricanCaribbean origin. Ethics approval was obtained from the relevant research ethics committee. Study methods have been published $[9,10,16]$. The study included 200 state primary schools in London, Birmingham and Leicester, half with a high prevalence of South Asian children (stratified by Indian, Pakistani and Bangladeshi origin) and half with a high prevalence of black African-Caribbean children (stratified by black African and black Caribbean origin). Written, informed consent was obtained for all participants and maternal permission sought to allow access to maternal health record information on the gestation and birth of the participant. Mothers were also asked to recall the hospital of birth, the birthweight of the child and whether the birth occurred on time, early or late and (if so) by how much.

Survey measurements Three trained research nurses measured participants between October 2004 and February 2007, each measuring approximately one-third of children in each ethnic group. Height and weight were measured and BMI calculated. Fat mass was determined from right-sided arm-to-leg bioelectrical impedance, using the Bodystat 1500 bioelectrical impedance monitor (Bodystat, Isle of Man); fat mass was derived using ethnicity- and sex-specific equations for children of this age group in the UK [17] and presented as a heightstandardised fat mass index [FMI; weight $(\mathrm{kg}) /$ height $\left.(\mathrm{m})^{5}\right]$, derived to be independent of height $(r=-0.02)$ [17]. FMI was preferred to BMI because of its greater validity in this multiethnic population [17]. BP was measured twice in the right arm using an Omron HEM-907 (Omron Electronics, Milton Keynes, UK) [18] with an appropriate cuff size [16]. Mean systolic and diastolic BP (two readings) were adjusted for errors in BP measurement arising from use of different cuff sizes using a previously validated method [19].

A blood sample was obtained after an overnight fast. Children were asked not to eat on the morning of the examination; those who reported having eaten breakfast were excluded from analyses. Serum for an insulin assay was separated and frozen on dry ice immediately after collection. Samples were shipped to a central laboratory within $48 \mathrm{~h}$. Serum insulin, plasma glucose, $\mathrm{HbA}_{1 \mathrm{c}}$ (measured in whole blood), serum blood lipids and serum C-reactive protein assays have previously been reported $[9,10]$. Serum urate was assayed using an enzymatic method [20]. HOMA equations [21] were used to calculate insulin resistance (HOMA-IR).

Ethnicity and socioeconomic status Participant ethnicity was defined as previously described [10] using self-reported parental ethnicity, where available (66\%), or parentally defined child ethnic origin $(33 \%)$, or using information on parental and grand-parental birth place provided by the child, crosschecked with observer assessment of ethnicity (1\%). Four broad ethnic categories were defined ('white European', 
'South Asian', 'black African-Caribbean', 'other'), with a more detailed ten-level ethnic categorisation used for adjustments (white European, Indian, Pakistani, Bangladeshi, other South Asian, other Asian, black African, black Caribbean, other black, other). Parental occupation obtained from parents or children was coded using the UK National Statistics Socioeconomic Classification (NS-SEC) for the parent with the highest classification (professional and managerial; intermediate; routine and manual; economically inactive; unclassified) [22].

Birthweight and gestational age Maternal medical record data on participant birthweight, gestational age and singleton/twin status were sought from several sources including: (1) the mother's hospital records; (2) hospital birth registers; (3) the North West Thames maternity database 19882000 for hospital births in the former North West Thames region; (4) the Health and Social Care Information Centre for all study children born in the UK with appropriate maternal consent (provided by $92 \%$ of mothers). Data were selected preferentially from sources (1) to (4); if no information was obtained, maternal recall data were used when available.

Statistical methods Statistical analyses were performed using STATA/SE software (Stata/SE 12 for Windows; StataCorp LP, College Station, TX, USA). All outcome variables except systolic and diastolic BP were positively skewed and a log transformation (base $e$ ) was used. Birthweight was approximately normally distributed. Low birthweight was defined as a birthweight $<2.5 \mathrm{~kg}$ [23]. Associations between birthweight and risk markers were examined, with birthweight fitted both in fifths and as a continuous variable. Departure from linearity was examined graphically (risk marker plotted against birthweight in fifths) and tested for by comparing models containing birthweight in fifths fitted either as a categorical or continuous variable. Continuous associations between birthweight and risk markers for type 2 diabetes and CVD were quantified as percentage differences (or absolute differences for BP) in each risk marker for a $100 \mathrm{~g}$ increase in birthweight using multilevel linear regression models adjusted for sex, age (in fourths), ethnic group (ten levels), socioeconomic position (five levels) and a random effect to allow for clustering of children within schools. The effects of additional adjustment for childhood height and FMI were examined, fitting these as continuous variables. Birthweight $\times$ height and birthweight $\times$ FMI interactions were also examined. To examine whether associations between birthweight and type 2 diabetes and CVD risk markers differed by sex or ethnic group, birthweight $\times$ sex and birthweight $\times$ ethnic group interaction terms were fitted. The effects of adjustment for gestational age and parity and of excluding mothers with gestational diabetes or parental recall of birthweight only on the associations between birthweight and risk markers were examined in sensitivity analyses.

\section{Results}

Of 8,641 children invited to participate, 5,887 (68\%) took part. Among 5,681 singleton children, 4,515 (79\%) provided a fasting blood sample and had complete risk marker measurements; $3,744(66 \%)$ also had data for birthweight, of whom $90 \%$ were born in the UK. These included 1,845 boys and 1,899 girls, 1,002 white Europeans, 1,025 South Asians, 863 black African-Caribbeans and 854 children of other ethnicity. Birthweight sources for these participants were hospital maternity records $(36.1 \%)$, hospital birth register $(5.6 \%)$, the North West Thames maternity database $(9.1 \%)$, Health and Social Care Information Centre data $(35.5 \%)$ and parental recall $(13.7 \%)$.

Birthweight patterns by sex and ethnic group are shown in Table 1 and birthweight patterns by ethnic subgroup are shown in Table 1 of the electronic supplementary material (ESM). Mean birthweight was $94 \mathrm{~g}$ higher in boys than in girls $(p<0.0001)$, although the prevalence of low birthweight $(<2.5 \mathrm{~kg})$ was similar $(8.0 \%$ and $8.3 \%$, respectively). Mean birthweight was lower in all ethnic minority groups, including South Asians (particularly Indians) and black AfricanCaribbean groups (particularly black Caribbeans), than in white Europeans. Prevalence of low birthweight was higher among South Asians and black African-Caribbeans than among white Europeans. Birthweight was moderately correlated with current childhood height $(r=0.20 ; p<0.0001)$ but was only weakly correlated with FMI $(r=0.04 ; p=0.02)$.

Associations between birthweight and risk markers for type 2 diabetes and CVD in individuals The continuous associations between birthweight and type 2 diabetes and CVD risk markers are shown in Table 2. Height-adjusted associations for fifths of birthweight are summarised graphically in ESM Fig. 1. The associations between birthweight and risk markers all appeared graded, with no evidence of U-shaped associations (tests for non-linearity, all $p>0.05$ ). In models including adjustments for age, sex, ethnic subgroup and school, there was an inverse association between birthweight and urate and a positive association with systolic BP; there were no appreciable associations of birthweight with insulin resistance (IR), glycaemia or blood lipids (Table 2). After additional adjustment for current childhood height, birthweight had a stronger inverse association with urate and was also inversely associated with fasting insulin, $\mathrm{HOMA}-\mathrm{IR}, \mathrm{HbA}_{1 \mathrm{c}}$, fasting glucose and triacylglycerol. In continuous associations, for each $100 \mathrm{~g}$ lower birthweight, the largest percentage increases were observed for urate, HOMA-IR and insulin. No consistent associations were observed for $\mathrm{C}$-reactive protein, LDL-cholesterol, HDL-cholesterol or BP. After separate adjustment for current childhood FMI (but without height), birthweight showed marginal inverse associations with triacylglycerol and urate but not with other risk markers. Combined 


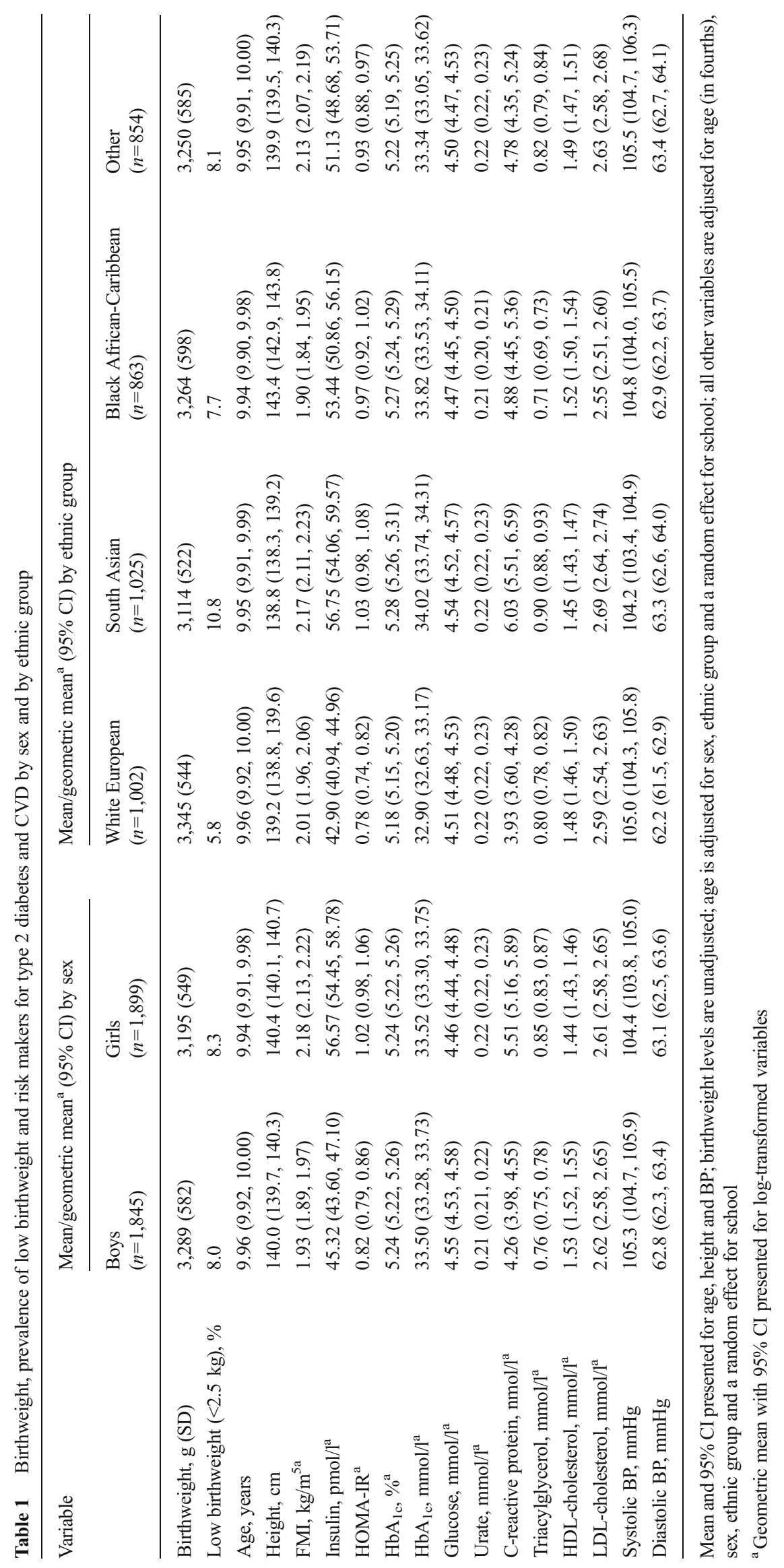


Table 2 Associations between birthweight and risk markers for type 2 diabetes and CVD with additional adjustments for childhood height and adiposity

\begin{tabular}{ll}
\hline Blood analyte and adjustment & $\begin{array}{l}\text { \% Difference/difference in } p \text { value } \\
\text { outcome for a } 100 \mathrm{~g} \\
\text { increase in birthweight } \\
(95 \% \mathrm{CI})\end{array}$
\end{tabular}

Insulin, $\mathrm{pmol} / 1$

Standard

Standard+height

Standard+FMI

Standard +height + FMI

HOMA-IR

Standard

Standard+height

Standard+FMI

Standard+height+FMI

$\mathrm{HbA}_{1 \mathrm{c}}, \%$

Standard

Standard+height

Standard+FMI

Standard +height + FMI

$\mathrm{HbA}_{1 \mathrm{c}}, \mathrm{mmol} / \mathrm{l}$

Standard

Standard+height

Standard+FMI

Standard+height+FMI

Glucose, $\mathrm{mmol} / \mathrm{l}$

Standard

Standard+height

Standard+FMI

Standard + height + FMI

Urate (mmol/l)

Standard

Standard+height

Standard+FMI

Standard +height + FMI

C-reactive protein, nmol/1

Standard

Standard+height

Standard+FMI

Standard+height+FMI

Triacylglycerol (mmol/l)

Standard

Standard+height

Standard+FMI

Standard+height+FMI

HDL-cholesterol, mmol/1

Standard

Standard+height

Standard+FMI

Standard + height + FMI

$\begin{array}{ll}0.28(-0.07,0.65) & 0.12 \\ -0.41(-0.74,-0.08) & 0.02 \\ -0.05(-0.36,0.27) & 0.76 \\ -0.72(-1.00,-0.43) & <0.0001\end{array}$

$0.24(-0.11,0.60) \quad 0.19$

$-0.44(-0.76,-0.11) \quad 0.01$

$-0.09(-0.40,0.23) \quad 0.60$

$-0.74(-1.02,-0.45) \quad<0.0001$

$-0.03(-0.06,0.01) \quad 0.12$

$-0.04(-0.08,0.00) \quad 0.03$

$-0.04(-0.07,0.00) \quad 0.05$

$-0.05(-0.08,-0.01) \quad 0.01$

$-0.05(-0.11,0.02) \quad 0.15$

$-0.07(-0.13,0.00) \quad 0.03$

$-0.06(-0.12,0.00) \quad 0.06$

$-0.08(-0.14,-0.02) \quad 0.01$

$-0.03(-0.08,0.01) \quad 0.16$

$-0.06(-0.10,-0.02) \quad 0.01$

$-0.04(-0.08,0.01) \quad 0.10$

$-0.06(-0.11,-0.02) \quad 0.004$

$-0.36(-0.50,-0.22) \quad<0.0001$

$-0.52(-0.66,-0.38) \quad<0.0001$

$-0.45(-0.58,-0.32) \quad<0.0001$

$-0.61(-0.74,-0.48) \quad<0.0001$

$0.47(-0.29,1.29) \quad 0.23$

$-0.23(-0.94,0.55) \quad 0.56$

$-0.36(-0.97,0.29) \quad 0.27$

$-0.99(-1.56,-0.37) \quad 0.002$

$-0.13(-0.34,0.08) \quad 0.23$

$-0.30(-0.51,-0.09) \quad 0.01$

$-0.26(-0.46,-0.06) \quad 0.01$

$-0.43(-0.63,-0.23) \quad<0.0001$

$-0.07(-0.19,0.04) \quad 0.22$

$0.04(-0.08,0.16) \quad 0.53$

$-0.01(-0.12,0.11) \quad 0.89$

$0.10(-0.01,0.22) \quad 0.08$
Table 2 (continued)

\begin{tabular}{lll}
\hline Blood analyte and adjustment & $\begin{array}{l}\text { \% Difference/difference in } \\
\text { outcome for a 100 g } \\
\text { increase in birthweight } \\
(95 \% \text { CI })\end{array}$ & $p$ value \\
\hline LDL-cholesterol, mmol/1 & & \\
Standard & $0.07(-0.07,0.21)$ & 0.34 \\
Standard+height & $0.12(-0.02,0.27)$ & 0.10 \\
Standard+FMI & $0.04(-0.10,0.18)$ & 0.61 \\
Standard+height+FMI & $0.09(-0.05,0.24)$ & 0.22 \\
Systolic BP, mmHg & & \\
Standard & $0.07(0.01,0.13)$ & 0.02 \\
Standard+height & $-0.03(-0.09,0.03)$ & 0.32 \\
Standard+FMI & $0.05(-0.01,0.11)$ & 0.12 \\
Standard+height+FMI & $-0.05(-0.11,0.00)$ & 0.07 \\
Diastolic BP, mmHg & & \\
Standard & & 0.43 \\
Standard+height & $0.02(-0.03,0.08)$ & 0.55 \\
Standard+FMI & $-0.02(-0.07,0.04)$ & 0.96 \\
Standard+height+FMI & $0.00(-0.05,0.05)$ & 0.18 \\
\hline
\end{tabular}

Percentage differences in outcome are presented for log-transformed variables (all except BP); standard adjustment is for sex, age (in fourths), NS-SEC group, ethnic subgroup and a random effect for school

${ }^{\text {a }}$ Absolute differences in BP are presented

adjustment for height and FMI increased the magnitude of the inverse associations observed after height adjustment between birthweight and fasting insulin, $\mathrm{HOMA}-\mathrm{IR}, \mathrm{HbA}_{1 \mathrm{c}}$, fasting glucose, urate and triacylglycerol. An inverse association between birthweight and C-reactive protein also appeared (Table 2).

The associations between birthweight and risk markers in models adjusted for height are shown separately by sex and by ethnic group with tests for interaction (ESM Table 2). Associations between birthweight and IR makers were stronger in girls compared with boys and in white Europeans compared with other ethnic groups. None of the birthweight-risk marker associations showed evidence of statistical interactions between birthweight and height or between birthweight and FMI (all $p>0.05$; ESM Table 2). Associations between birthweight in fifths and risk markers are shown in ESM Table 3 to allow for the possibility of nonlinearity in these associations. This showed similar patterns to the continuous associations presented in Table 2.

Associations between birthweight and risk markers with cumulative adjustments for gestational age and parity are shown in ESM Table 4. Associations between birthweight and fasting insulin, HOMA-IR and urate were little affected by gestational age adjustment; the association with $\mathrm{HbA}_{1 \mathrm{c}}$ was strengthened and those with fasting glucose and triacylglycerol were weakened by approximately one-third. Additional 
adjustment for parity did not appreciably affect associations between birthweight and risk markers. Exclusion of 94 participants born to mothers with gestational diabetes or 512 participants for whom birthweight data were based on parental recall (rather than medical records) had no material effect on these associations (ESM Table 5).

Ethnic differences in risk markers for type 2 diabetes and CVD: the contribution of birthweight Ethnic differences in risk markers for type 2 diabetes and CVD in this study population have previously been reported [9, 10]. Ethnic patterns in risk markers in the 3,744 singleton children with birthweight data are shown in Table 1 and ethnic differences in risk markers for CVD are shown in Table 3 (South Asianswhite Europeans) and Table 4 (black African-Caribbeanswhite Europeans). Compared with white Europeans, South Asians had similar mean age and height. Their mean FMI, fasting insulin, $\mathrm{HOMA}-\mathrm{IR}, \mathrm{HbA}_{1 \mathrm{c}}$, fasting glucose, C-reactive protein, triacylglycerol, LDL-cholesterol and diastolic BP were higher; mean HDL-cholesterol was lower. Compared with white Europeans, black African-Caribbeans were taller and had a lower mean FMI. They had higher mean levels of fasting insulin, HOMA-IR, $\mathrm{HbA}_{1 \mathrm{c}}$, HDL-cholesterol and diastolic BP, and lower mean levels of fasting glucose, urate, triacylglycerol and systolic BP.

The effects of birthweight adjustment on ethnic differences in risk markers between South Asians, South Asian subgroups (Indian, Pakistani, Bangladeshi) and white Europeans in height-standardised models are shown in Table 3. In comparisons with white Europeans, the markedly higher mean levels of fasting insulin, HOMA-IR, $\mathrm{HbA}_{1 \mathrm{c}}$, glucose, C-reactive protein, triacylglycerol and diastolic BP among South Asians were minimally affected by birthweight adjustment (being reduced by between $14 \%$ for fasting glucose and $2 \%$ for C-reactive protein); the lower HDL-cholesterol levels in South Asians were little affected. Birthweight adjustment had similarly little impact on the magnitude of ethnic differences in the South Asian subgroups, including the larger differences in fasting insulin, urate, triacylglycerol and HDL-cholesterol for Bangladeshis.

The effects of birthweight adjustment on ethnic differences in risk markers between black African-Caribbeans (and black Africans and black Caribbeans separately) and white Europeans in height-standardised models are shown in Table 4. In comparison with white Europeans, the markedly higher mean levels of fasting insulin, HOMA-IR, $\mathrm{HbA}_{1 \mathrm{c}}$ and HDL-cholesterol in black African-Caribbeans were largely unaffected by birthweight adjustment; the lower mean levels of urate, triacylglycerol and systolic BP were similarly little affected by birthweight adjustment. Adjustment for birthweight similarly had little impact on the magnitude of ethnic differences in the separate black African-Caribbean subgroups, including the larger differences in fasting insulin in black Caribbeans and the lower urate, triacylglycerol and systolic BP levels in black Africans. In parallel analyses without height adjustment (ESM Tables 6 and 7 for South Asians and black Africans, respectively), similar results were observed; birthweight adjustment had very little effect on ethnic differences in risk markers. Repeating these analyses fitting birthweight as a dichotomous variable $(<2.5 \mathrm{~kg}$, $\geq 2.5 \mathrm{~kg}$ ) did not materially affect the results (data available from authors).

\section{Discussion}

In this multiethnic study of prepubertal children, birthweight was associated with some risk markers for type 2 diabetes and CVD, although these were in most cases dependent on adjustment for childhood size (particularly height). In analyses unadjusted for childhood size, birthweight was inversely associated with serum urate and positively associated with systolic BP but not notably related to other risk markers. After adjustment for childhood height, birthweight was inversely associated not only with urate but also with fasting insulin, HOMA-IR, $\mathrm{HbA}_{1 \mathrm{c}}$, fasting glucose and triacylglycerol. Further adjustment for FMI strengthened many of these height-adjusted associations. The associations between birthweight, fasting insulin and HOMA-IR tended to be stronger in girls and in white Europeans; associations with other risk markers were mostly consistent across sexes and ethnic groups. The associations were little affected by gestational age, parity adjustment or exclusion of mothers with gestational diabetes. There were marked ethnic differences in type 2 diabetes risk markers, with IR being higher among South Asians and to a lesser extent black African-Caribbeans compared with white Europeans, while mean birthweight was lower among South Asians and to a lesser extent black AfricanCaribbeans. However, adjustment for differences in birthweight did not account for ethnic differences in risk markers.

Relation to previous studies In the present study, birthweight was inversely associated with IR and its correlates (including triacylglycerol and urate). This is consistent with the results of most population-based studies including $250+$ prepubertal children [6, 12, 13, 24-26], though not all [27, 28]. As in most studies reporting an inverse association between birthweight and IR, this was only apparent after adjustment for current size $[13,24]$. In the present study, as in an earlier report [12], adjustment for height alone produced the inverse birthweight-IR association, although adjustment for body fatness alone did not reveal the association. An inverse birthweight-IR association has previously been reported in white Europeans [12, 13], in Indians [24] and in Africanorigin populations [26]. No previous studies have compared 


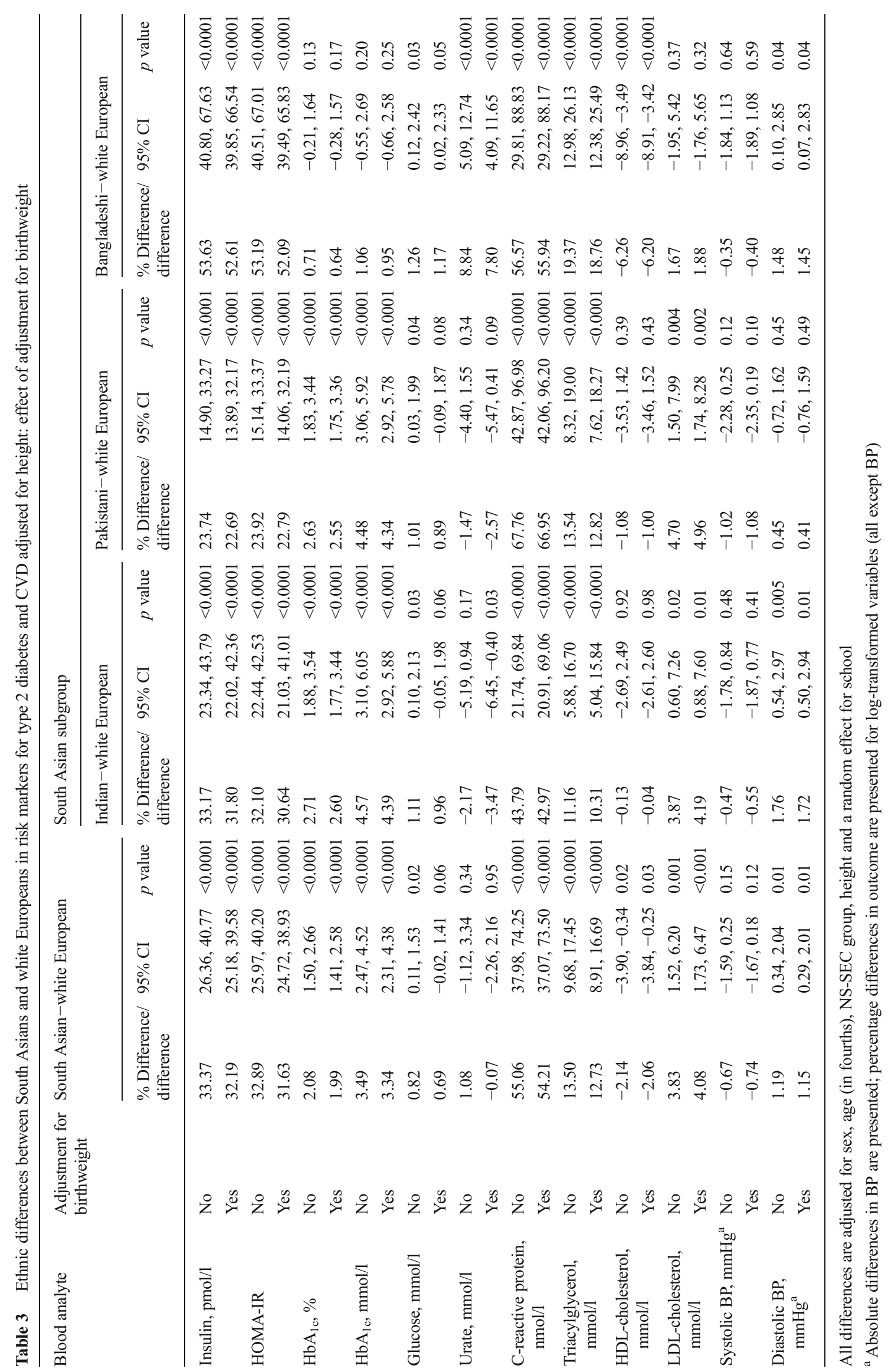




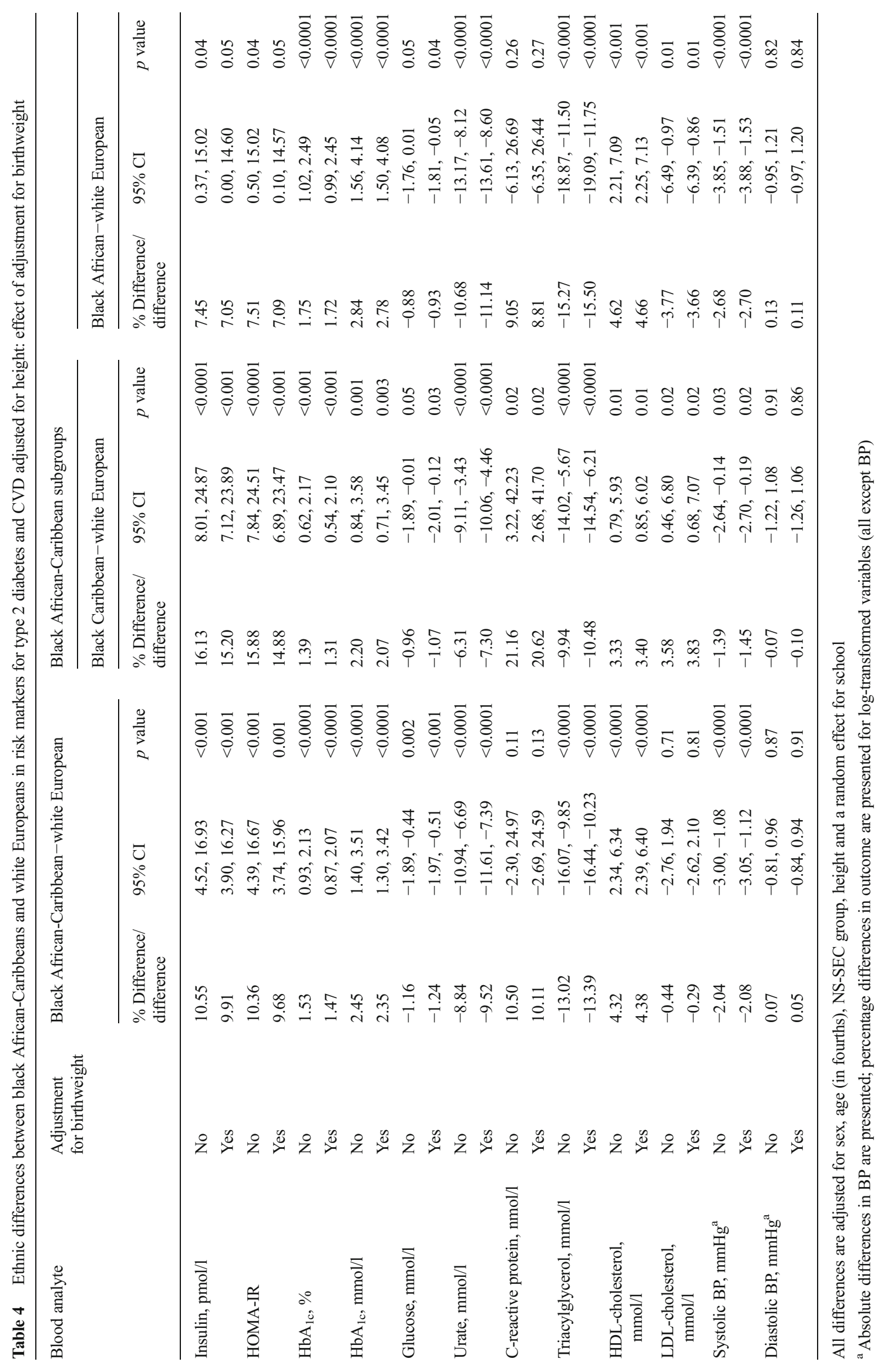


the strength of birthweight-IR associations among South Asians and white Europeans, although in the Bogalusa Heart Study this association was slightly stronger among AfricanAmericans than among whites [26]. The inverse association, after adjustment for current size, between birthweight and circulating glucose levels (both fasting glucose and $\mathrm{HbA}_{1 \mathrm{c}}$ ) observed in the present study has been widely reported in adults [3] but has been reported in only one previous study in children [25], with a further study reporting an inverse association for ponderal index at birth [28]. Several other relevant studies reported null associations [13, 24, 27]. However, positive birthweight-glucose associations have been reported in Aboriginal child populations [13, 29] as in adults [30]. The inverse association detected in the present study may reflect the greater size and statistical power of the present study compared with previous investigations. The inverse association observed between birthweight and circulating urate (apparent without adjustment for height in the present study) is consistent with several earlier reports [27, 31, 32]. Although those reports tended to emphasise the role of urate in developing hypertension [31,32], in the present study urate was associated with fasting insulin $(r=0.21)$ and only weakly with systolic or diastolic BP $(r=0.11$ and 0.08 , respectively), although a large Mendelian randomisation study suggested that urate had no causal role in the development of type 2 diabetes [33]. Despite several previous reports suggesting that birthweight is inversely associated with childhood BP after adjustment for current size [34], we observed no inverse associations between birthweight and BP in the present study, even after adjustment for current size. The absence of any appreciable association between birthweight and LDLcholesterol is consistent with previous systematic review evidence based on studies both in children and adults [35].

Although fetal undernutrition could contribute to ethnic differences in risks of type 2 diabetes and CVD (especially the high risks in South Asians) [5], this is to our knowledge the first study to examine the contribution of birthweight to ethnic differences in relevant risk markers. The absence of an appreciable contribution of birthweight (or the presence of low birthweight, $<2.5 \mathrm{~kg}$ ) to South Asian/white European differences in markers of IR (despite a mean difference of $\sim 250 \mathrm{~g}$ in birthweight between these groups) is consistent with earlier reports in adults suggesting that a $250 \mathrm{~g}$ difference in birthweight would only explain a $7-10 \%$ difference in type 2 diabetes risk [3], rather than the three- to fourfold difference actually observed [6].

Strengths and limitations Strengths of this study include its large sample size and balanced representation of children of South Asian (including Indian, Pakistani, Bangladeshi), black African-Caribbean (including black African, black Caribbean) and white European origin from three major UK cities; the measurement of important early risk markers for type 2 diabetes (particularly fasting glucose, $\mathrm{HbA}_{1 \mathrm{c}}$ and markers of IR including fasting insulin, HOMA-IR and urate [36]; and the measurement of important early risk markers for CVD (particularly LDL-cholesterol and BP). Although the study response rate was only moderate, mean birthweight levels and low birthweight prevalences among the different ethnic groups in the present study were similar to those in national data [11], suggesting that the study population was substantially representative for the key exposure studied. FMI derived from bioelectrical impedance and used with validated ethnicity- and sex-specific equations [17] provided a robust marker of body fatness in this multiethnic population [17]. Although the device used to measure BP (Omron HEM-907) has not been validated in children, validation studies in adults showed that the performance of the instrument was similar at different BP levels [18]. Several data sources were used to obtain contemporaneously recorded birthweight data from health records. Parental recall data (which showed very close agreement with health record data in 1,779 participants with birthweight data from both sources) were available for a further $14 \%$ of participants. Study participants with birthweight data (83\%) had similar risk marker profiles to those of participants without birthweight data. Birthweight patterns observed among study participants (including both sex and ethnic differences) corresponded closely with those for the UK overall [11]. In analyses of associations between birthweight, diabetes and cardiovascular risk, we explored the impact of specific components of current body size and were able to make adjustments for potential confounders including gestational age, socioeconomic status, parity and gestational diabetes. However, this study was not able to capture ethnic differences in body composition at birth other than those in birthweight; recent reports have suggested that South Asian infants in the UK have higher fat mass and differences are not well captured by birthweight [37].

Implications Our results suggest that lower birthweight is associated with higher levels of IR and circulating glucose concentrations in this multiethnic childhood population, though not with cardiovascular risk markers. With the exception of urate, these associations appear to be dependent on adjustment for current height (though not on current body fatness, a measure which is completely independent of height). Such adjusted models effectively attempt to estimate the longer term effect of lower birthweight on disease risk while standardising for current height [12], and may reflect the growth trajectories taken to reach current body size [38]. Such standardisation for childhood height appears reasonable: height is strongly positively associated with IR and its correlates during childhood, but the association is attenuated, or reversed, by early adult life $[12,13]$. Conversely, body fatness is positively associated with IR and its correlates in adulthood as well as in childhood [39], and in the present study it did not 
appear to be a confounder in models unadjusted for height. Thus, standardisation of birthweight-risk marker associations for current body fatness may be inappropriate and represent overadjustment [15]. The associations between birthweight, IR and glycaemia, though varying by sex and ethnic group, are graded, not appreciably altered by adjustment for observed confounders and consistent with the findings of other studies, suggesting that there may be an important underlying causal association with potential implications for type 2 diabetes prevention. Defining the strength of the underlying causal associations is important for assessing both causality and the preventive potential of birthweight modification. Based on the observed associations, a potentially feasible increase in birthweight ( $\sim 100 \mathrm{~g}$ ) could reduce IR by $\sim 0.4 \%$ and glucose concentrations by $0.04-0.06 \%$. These associations are small; substantially greater reductions could potentially be obtained by moderate reductions in childhood body fatness [39] or energy intake [40]. However, such interpretation depends on the underlying causal association, as low birthweight could denote a considerably stronger and potentially important association between early nutrition and subsequent disease risk $[5,12]$. It is also possible that strategies to improve fetal nutrition, for example through maternal nutritional supplementation, could benefit offspring health independently of birthweight [41].

Previous reports have raised the possibility that low birthweight, as a marker of fetal undernutrition, could help to explain ethnic differences in type 2 diabetes and cardiovascular risk $[5,10]$. However, the results of the present study suggest that ethnic differences in birthweight do not make an important contribution to explaining ethnic differences in IR and glycaemia between South Asians, black AfricanCaribbeans and white Europeans. This particularly reflects the small sizes of the associations between birthweight, insulin and glycaemia in individual participants, so that adjustment for the observed ethnic differences in mean birthweight (more than $200 \mathrm{~g}$ between South Asians and white Europeans) had little effect on ethnic differences in IR and glycaemia. However, this does not exclude the possibility that other factors operating in utero or at birth, including maternal nutrition and maternal glucose control [42] and body composition at birth (e.g. body fatness [37]), could be important determinants of ethnic differences in diabetes or cardiovascular risk. However, in seeking the causes of high emerging type 2 diabetes risks among South Asians and black AfricanCaribbeans in the UK, it will also be important to consider the later influences of childhood overweight, nutrition (including energy intake), physical activity and fitness [39, 40, 43].

Acknowledgements We thank the CHASE field study team members and all participating schools, pupils and parents. We are grateful to the custodians for access to the North West Thames maternity database
1988-2000, to the Health and Social Care Information Centre for providing birthweight data, and to the relevant hospital trusts and their staff for allowing and arranging access to maternal health records (list provided in ESM Acknowledgements).

Funding This investigation (including the costs of maternal medical record retrieval) was supported by a project grant from Diabetes UK (grant reference 11/0004226). Data collection in CHASE was supported by grants from the Wellcome Trust (grant reference 068362/Z/02/Z) and the National Prevention Research Initiative (NPRI; grant reference G0501295). The funding partners for this NPRI award were: British Heart Foundation; Cancer Research UK; Department of Health; Diabetes UK; Economic and Social Research Council; Medical Research Council; Research and Development Office for the Northern Ireland Health and Social Services; Chief Scientist Office, Scottish Executive Health Department; and Welsh Assembly Government. Diabetes prevention research at St George's, University of London, is supported by the National Institute of Health Research (NIHR) Collaboration for Leadership in Applied Health Research and Care, South London. The views expressed in this paper are those of the authors and not necessarily those of the funding agencies, the National Health Service, the NIHR or the Department of Health.

Duality of interest The authors declare that there is no duality of interest associated with this manuscript.

Contribution statement $\mathrm{PHW}$ and CMN developed the idea for this paper with help from ARR, CGO, PJS, DAL, NS and DGC. PHW conceived, raised funding for and directed CHASE, with help from DGC, CGO, ARR, NS and ASD. SLN, JLB, ASD and CM collected data. CMN carried out the statistical analyses and wrote the first draft of the paper. All authors critically reviewed the scientific content and approved the final version to be published. Claire Nightingale is the guarantor of this work.

Open Access This article is distributed under the terms of the Creative Commons Attribution License which permits any use, distribution, and reproduction in any medium, provided the original author(s) and the source are credited.

\section{References}

1. Barker DJ (2012) Sir Richard Doll lecture. Developmental origins of chronic disease. Publ Health 126:185-189

2. Kuh DL, Ben-Shlomo Y (1997) A life course approach to chronic disease epidemiology. Oxford University Press, Oxford

3. Whincup PH, Kaye SJ, Owen CG et al (2008) Birth weight and risk of type 2 diabetes: a systematic review. JAMA 300:2886-2897

4. Huxley R, Owen CG, Whincup PH et al (2007) Is birth weight a risk factor for ischemic heart disease in later life? Am J Clin Nutr $85: 1244-1250$

5. Bhopal RS (2013) A four-stage model explaining the higher risk of type 2 diabetes mellitus in South Asians compared with European populations. Diabet Med 30:35-42

6. Sproston K, Mindell J (eds) (2006) Health survey for England 2004: the health of ethnic minority groups. The Information Centre, Leeds

7. Shai I, Jiang R, Manson JE et al (2006) Ethnicity, obesity, and risk of type 2 diabetes in women: a 20 -year follow-up study. Diabetes Care 29:1585-1590 
8. Wild SH, Fischbacher C, Brock A, Griffiths C, Bhopal R (2007) Mortality from all causes and circulatory disease by country of birth in England and Wales 2001-2003. J Publ Health (Oxf) 29:191-198

9. Donin AS, Nightingale CM, Owen CG et al (2010) Ethnic differences in blood lipids and dietary intake between UK children of black African, black Caribbean, South Asian, and white European origin: the Child Heart and Health Study in England (CHASE). Am J Clin Nutr 92:776-783

10. Whincup PH, Nightingale CM, Owen CG et al (2010) Early emergence of ethnic differences in type 2 diabetes precursors in the UK: the Child Heart and Health Study in England (CHASE Study). PLoS Med 7:e1000263

11. Moser K, Stanfield KM, Leon DA (2008) Birthweight and gestational age by ethnic group, England and Wales 2005: introducing new data on births. Health Stat Q 22-55

12. Lawlor DA, Riddoch CJ, Page AS et al (2005) The association of birthweight and contemporary size with insulin resistance among children from Estonia and Denmark: findings from the European Youth Heart Study. Diabet Med 22:921-930

13. Whincup PH, Cook DG, Adshead F et al (1997) Childhood size is more strongly related than size at birth to glucose and insulin levels in 10-11-year-old children. Diabetologia 40:319-326

14. Tu YK, West R, Ellison GT, Gilthorpe MS (2005) Why evidence for the fetal origins of adult disease might be a statistical artifact: the 'reversal paradox' for the relation between birth weight and blood pressure in later life. Am J Epidemiol 161:27-32

15. Whincup PH (1998) Fetal origins of cardiovascular risk: evidence from studies in children. Proc Nutr Soc 57:123-127

16. Thomas C, Nightingale CM, Donin AS et al (2012) Ethnic and socioeconomic influences on childhood blood pressure: the Child Heart and Health Study in England. J Hypertens 30:2090-2097

17. Nightingale CM, Rudnicka AR, Owen CG et al (2013) Are ethnic and gender specific equations needed to derive fat free mass from bioelectrical impedance in children of South Asian, black AfricanCaribbean and white European origin? Results of the Assessment of Body Composition in Children Study. PLoS One 8:e76426

18. White WB, Anwar YA (2001) Evaluation of the overall efficacy of the Omron office digital blood pressure HEM-907 monitor in adults. Blood Press Monit 6:107-110

19. Whincup PH, Cook DG, Shaper AG (1989) Blood pressure measurement in children: the importance of cuff bladder size. J Hypertens 7 : $845-850$

20. Fossati P, Prencipe L, Berti G (1980) Use of 3,5-dichloro-2hydroxybenzenesulfonic acid/4-aminophenazone chromogenic system in direct enzymic assay of uric acid in serum and urine. Clin Chem 26:227-231

21. Levy JC, Matthews DR, Hermans MP (1998) Correct homeostasis model assessment (HOMA) evaluation uses the computer program. Diabetes Care 21:2191-2192

22. Office for National Statistics (2005) The national statistics socioeconomic classification user manual. Palgrave Macmillan, Basingstoke

23. Li C, Johnson MS, Goran MI (2001) Effects of low birth weight on insulin resistance syndrome in Caucasian and African-American children. Diabetes Care 24:2035-2042

24. Bavdekar A, Yajnik CS, Fall CH et al (1999) Insulin resistance syndrome in 8 -year-old Indian children: small at birth, big at 8 years, or both? Diabetes 48:2422-2429

25. Krishnaveni GV, Veena SR, Hill JC, Kehoe S, Karat SC, Fall CH (2010) Intrauterine exposure to maternal diabetes is associated with higher adiposity and insulin resistance and clustering of cardiovascular risk markers in Indian children. Diabetes Care 33:402-404
26. Mzayek F, Sherwin R, Fonseca Vet al (2004) Differential association of birth weight with cardiovascular risk variables in AfricanAmericans and Whites: the Bogalusa Heart Study. Ann Epidemiol $14: 258-264$

27. Kaneshi T, Yoshida T, Ohshiro T, Nagasaki H, Asato Y, Ohta T (2007) Birthweight and risk factors for CVDs in Japanese schoolchildren. Pediatr Int 49:138-143

28. Law CM, Gordon GS, Shiell AW, Barker DJ, Hales CN (1995) Thinness at birth and glucose tolerance in seven-year-old children. Diabet Med 12:24-29

29. Sayers SM, Mott SA, Mann KD, Pearce MS, Singh GR (2013) Birthweight and fasting glucose and insulin levels: results from the Aboriginal Birth Cohort Study. Med J Aust 199:112-116

30. McNamara BJ, Gubhaju L, Chamberlain C, Stanley F, Eades SJ (2012) Early life influences on cardio-metabolic disease risk in aboriginal populations - what is the evidence? A systematic review of longitudinal and case-control studies. Int J Epidemiol 41:16611682

31. Franco MC, Christofalo DM, Sawaya AL, Ajzen SA, Sesso R (2006) Effects of low birth weight in 8- to 13-year-old children: implications in endothelial function and uric acid levels. Hypertension 48:45-50

32. Park B, Park E, Cho SJ et al (2009) The association between fetal and postnatal growth status and serum levels of uric acid in children at 3 years of age. Am J Hypertens 22:403-408

33. Pfister R, Barnes D, Luben R et al (2011) No evidence for a causal link between uric acid and type 2 diabetes: a Mendelian randomisation approach. Diabetologia 54:2561-2569

34. Huxley R, Neil A, Collins R (2002) Unravelling the fetal origins hypothesis: is there really an inverse association between birthweight and subsequent blood pressure? Lancet 360:659-665

35. Huxley R, Owen CG, Whincup PH, Cook DG, Colman S, Collins R (2004) Birth weight and subsequent cholesterol levels: exploration of the 'fetal origins' hypothesis. JAMA 292:2755-2764

36. Kodama S, Saito K, Yachi Y et al (2009) Association between serum uric acid and development of type 2 diabetes. Diabetes Care 32: $1737-1742$

37. West J, Lawlor DA, Fairley L et al (2013) UK-born Pakistaniorigin infants are relatively more adipose than white British infants: findings from 8704 mother-offspring pairs in the Born-in-Bradford prospective birth cohort. J Epidemiol Community Health 67:544-551

38. Lucas A, Fewtrell MS, Cole TJ (1999) Fetal origins of adult diseasethe hypothesis revisited. BMJ 319:245-249

39. Nightingale CM, Rudnicka AR, Owen CG et al (2013) Influence of adiposity on insulin resistance and glycemia markers among United Kingdom children of South Asian, black African-Caribbean, and white European origin: Child Heart and Health Study in England. Diabetes Care 36:1712-1719

40. Donin AS, Nightingale CM, Owen CG et al (2014) Dietary energy intake is associated with type 2 diabetes risk markers in children. Diabetes Care 37:116-123

41. Skilton MR, Raitakari OT, Celermajer DS (2013) High intake of dietary long-chain omega-3 fatty acids is associated with lower blood pressure in children born with low birth weight: NHANES 20032008. Hypertension 61:972-976

42. Yajnik CS (2004) Early life origins of insulin resistance and type 2 diabetes in India and other Asian countries. J Nutr 134:205-210

43. Owen CG, Nightingale CM, Rudnicka AR, Cook DG, Ekelund U, Whincup PH (2009) Ethnic and gender differences in physical activity levels among 9-10-year-old children of white European, South Asian and African-Caribbean origin: the Child Heart Health Study in England (CHASE Study). Int J Epidemiol 38:1082-1093 